\title{
MONITORAMENTO DO PERCEVEJO-PRETO EM AMENDOIM ATRAVES DE ARMADILHA LUMINOSA
}

Wilton Marcos de Souza ${ }^{1}$; Cintia Michele Ferreira Mendes²; Rogério Soares de Freitas ${ }^{3}$; Ignácio José Godoy $^{4}$; Cristiano Feldens Schwertner ${ }^{5}$ Marcos Doniseti Michelotto ${ }^{6}$

1'Graduando em Agronomia, UNIRP, São José do Rio Preto, SP, wilton.s@live.com; 2Graduando em Agronomia, UNIRP, São José do Rio Preto, SP; ${ }^{3}$ Pesquisador Cientíco APTA, Votuporanga, SP; ${ }^{4}$ Pesquisador Cientíco do IAC, Campinas, SP; ${ }^{5}$ Pesquisador Cientíco do IAC, Campinas, SP; ${ }^{6}$ Pesquisador Cientíco APTA, Pindorama, SP.

RESUMO: As informações relacionadas à ocorrência e flutuação populacional do percevejopreto, Cyrtomenus mirabilis (Perty, 1836) (Hemiptera: Cydnidae) ao longo do ciclo do amendoim são escassas. O inseto ataca as vagens do amendoim, danificando os grãos, tornando-os impróprios para comercialização. O objetivo deste trabalho foi avaliar a flutuação populacional do percevejo-preto em função do ciclo da cultura do amendoim, em três localidades do Estado de São Paulo. Foram instaladas armadilhas luminosas nas três áreas e inspeções foram feitas semanalmente para a contagem de percevejos adultos, que posteriormente foram separados e identificados. De posse dos resultados, foram elaborados gráficos de flutuação dos insetos em função do ciclo de desenvolvimento das plantas de amendoim na área. A armadilha luminosa foi eficiente para captura do percevejo-preto em amendoim; Os maiores picos de ocorrência do percevejo-preto foram no início do desenvolvimento da cultura do amendoim. Aos 60 DAS, quando as plantas de amendoim começaram a ter as primeiras vagens com grãos maduros ocorreu a redução no número de indivíduos capturados nas armadilhas.

Palavras-chave:Arachis hypogaea; praga-de-solo, monitoramento.

\section{INTRODUÇÃO}

O amendoim, Arachis hypogaea L. é atacado por numerosas pragas que causam danos. Estes danos vão desde alimentação acidental até total destruição da planta e perdas de produção. Segundo SMITH \& BARFIELD (1982) o amendoim é atacado por mais de 360 espécies de insetos em todo o mundo. No Brasil são citadas como pragas da cultura cerca de 20 espécies de insetos, atacando em alguma fase de desenvolvimento das plantas.

O percevejo-preto, Cyrtomenus mirabilis (Perty, 1836) (Hemiptera: Cydnidae) é considerada uma espécie importante nas culturas de amendoim no Peru, Paraguai, Argentina e Brasil (FROESCHNER 1960, ZUCCHIET al. 1993, GALLO et al. 2002). No Brasil, os danos decorrentes de C. mirabilis estão relacionados ao ataque em vagens na fase de desenvolvimento dos grãos, na qual 
ninfas e adultos através do estilete de seu aparelho bucal atingem os grãos em desenvolvimento. Ao se alimentarem dos grãos, os mesmos tornam-se manchados impróprios para comercialização. Os prejuízos podem ser de grande magnitude ao considerar o mercado de amendoim blancheado (sem pele) e ao fato de esses ferimentos servirem como porta de entrada a fungos produtores de aflatoxina.

O conhecimento da flutuação populacional de um inseto permite a obtenção de informações importantes para o desenvolvimento de métodos de controle populacional de pragas (GILBERT et al., 1976). São importantes também em estudos relacionados à distribuição e à abundância de um inseto, oferecendo subsídios para a previsão da ocorrência de pragas e adoção de estratégias de controle (HIGLEY et al., 1986).

Apesar da importância do percevejo-preto como praga em amendoim, as informações sobre sua ocorrência ao longo do ciclo do amendoim são escassas. Uma das maneiras de se realizar o monitoramento dos percevejos-escavadores, como são chamados os percevejos de solo, é o uso de armadilhas luminosas. Dessa forma, o objetivo deste trabalho foi avaliar a flutuação populacional do percevejo-preto através de armadilhas luminosas em três localidades do Estado de São Paulo.

\section{MATERIAL E MÉTODOS}

As armadilhas luminosas foram instaladas em três localidades do Estado de São Paulo, Pindorama (Polo Centro Norte/Apta), Ribeirão Preto (Centro de Cana/IAC) e Votuporanga (Centro de Seringueira/IAC). Estes locais foram escolhidos por terem apresentado histórico de ocorrência de grãos com danos do percevejo na safra 2016/17.

A armadilha foi instalada em um suporte de ferro de 2,0 metros de altura para evitar que as mesmas ficassem em contato com as plantas de amendoim. A lâmpada fluorescente de cor branca foram acionadas através de um "timer" ao anoitecer. A mesma foi alimentada por uma bateria $12 \mathrm{v}$ recarregada por uma placa solar (Figura 1).

Essas armadilhas foram inspecionadas semanalmente para a contagem de adultos dos percevejos, que foram devidamente separados e identificados. Em Pindorama, os mesmos foram levados para o laboratório do Polo Centro Norte, separados e armazenados em álcool etílico. Em Votuporanga, foi adotado o mesmo procedimento, porém a separação foi realizada no laboratório do Centro de Seringueira. Em Ribeirão Preto, os insetos foram levados para Centro de Cana em Ribeirão Preto, SP. As armadilhas foram instaladas no início de setembro e permaneceram nos locais até a colheita do amendoim.

De posse dos resultados, foram elaborados gráficos de flutuação dos insetos em função do ciclo de desenvolvimento das plantas de amendoim na área. 


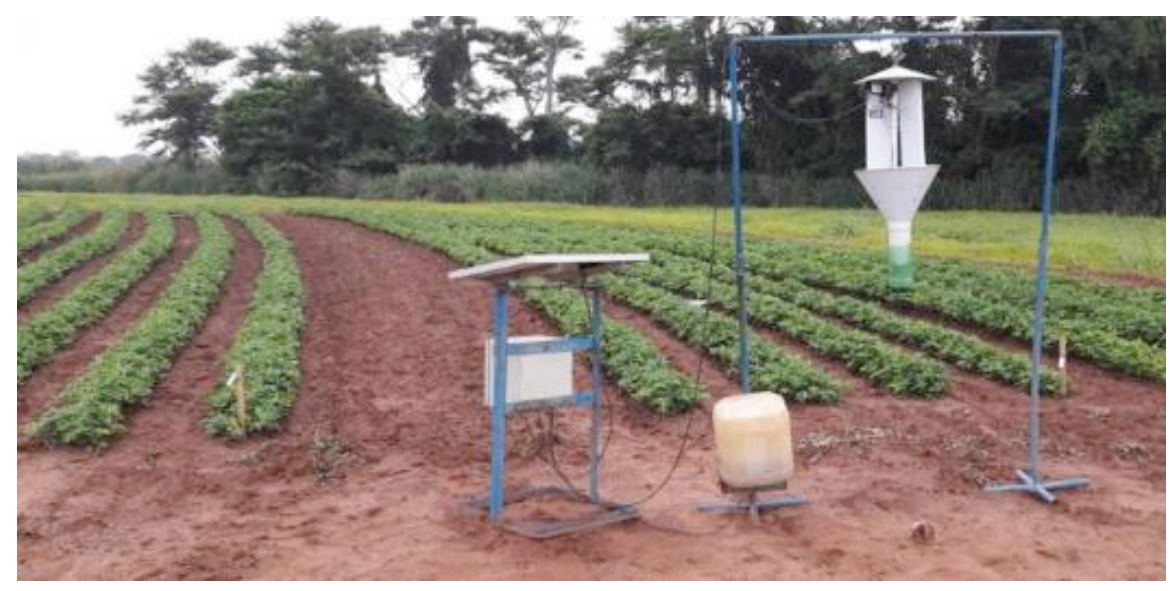

Figura 1. Detalhe da armadilha luminosa instalada em Pindorama, SP. Safra 2017/18.

\section{RESULTADOS E DISCUSSÕES}

Nos três locais foram capturados ao todo cerca de 1000 percevejos, conforme Figura 2.Em Pindorama na primeira data de coleta foram capturados 400 adultos do percevejo-preto, o maior pico de ocorrência em todo o período de avaliação. Posteriormente houve um decréscimo na captura de adultos e a partir dos 56 DASe houve um pequeno pico de ocorrência aos 136 DAS, data em que o amendoim estava pronto para ser colhido.

Uma provável causa para tal comportamento pode estar relacionado com a oferta de alimento, uma vez que após os 60 DAS as plantas de amendoim começam a ter as primeiras vagens com grãos maduros. De acordo com SMITH \& PITTS (1974) ninfas e adultos de Pangaeus bilineatus (Say), espécie que ocorre nos Estados Unidos e que causa danos semelhantes ao amendoim, preferem se alimentar de grãos já formados e maduros, provavelmente por conterem menor teor de água em seu conteúdo.

Em Votuporanga observou-se as mesmas características de Pindorama com um pico de insetos aos 35 DAS com 36 adultos em 10 dias e posterior decréscimo até os 66 DAS quando não foram coletados. Após este período, somente 6 indivíduos foram coletados até a colheita do amendoim (Figura 2).

Em Ribeirão Preto pico de coleta foi aos 44 DAS com 91 insetos coletados e posterior queda. No entanto, entre os dias 06 e 10 de janeiro de 2018 ocorreu o furto da armadilha e optou-se por não instalar outro equipamento em função do alto risco de ocorrer outro furto. 
16 e 17 de agosto de 2018, centro de convenções da FCAV/UNESP - Câmpus de Jaboticabal, SP
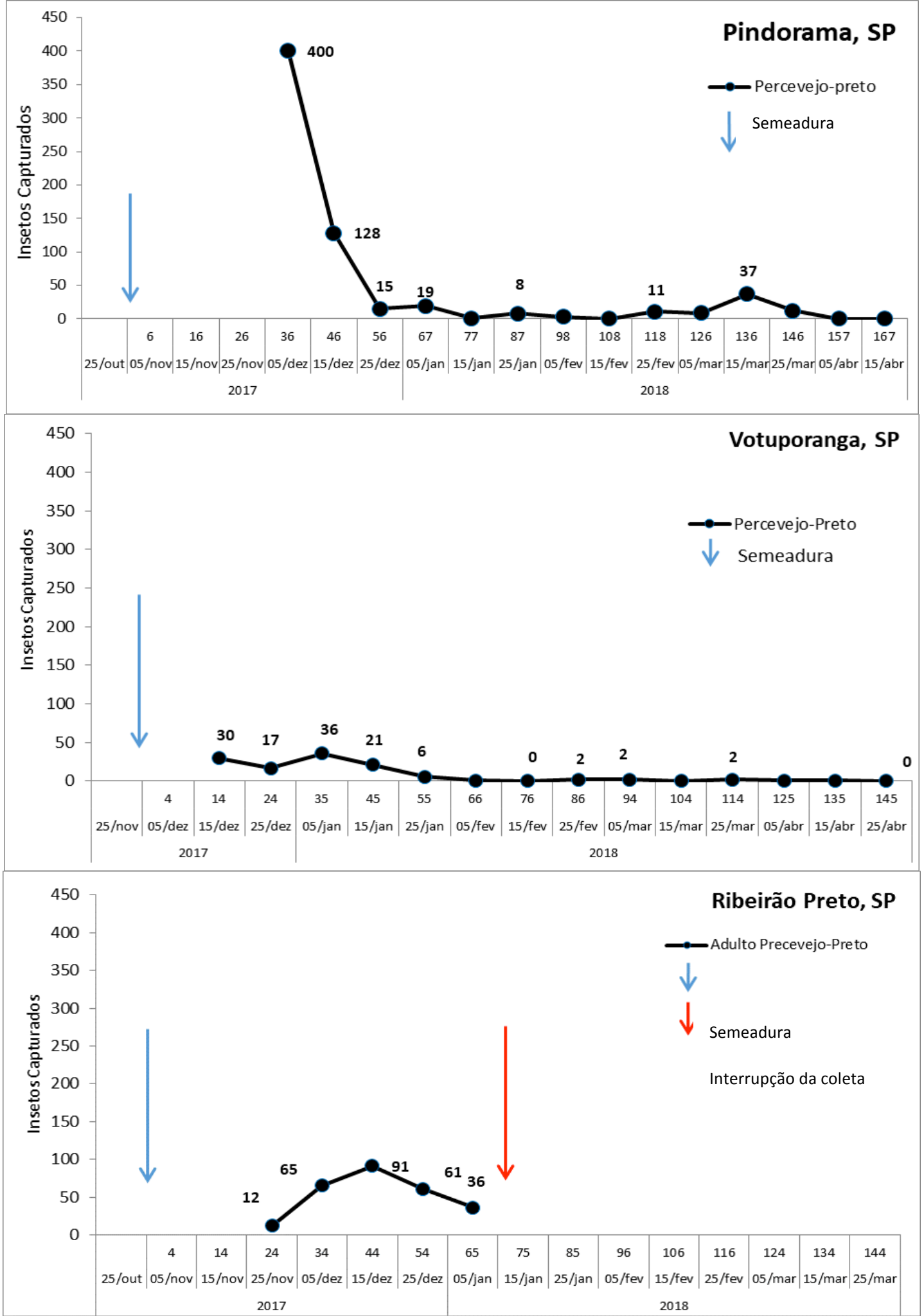

Figura 2. Flutuação de adultos do percevejo-preto, Cyrtomenus mirabilis através de armadilha luminosa na cultura do amendoim em Pindorama, Votuporanga e Ribeirão Preto, SP. Safra 2017/18. 


\section{CONCLUSÃO}

As armadilhas luminosas podem ser utilizadas para o monitoramento de adultos do percevejopreto no amendoim.

Os maiores picos de ocorrência do percevejo-preto ocorrem no início do desenvolvimento da cultura do amendoim.

Após a presença das primeiras vagens de amendoim com grãos maduros há redução no número de indivíduos capturados pelas armadilhas.

\section{REFERENCIAS BIBLIOGRÁFICAS}

FROESCHNER, R.C. Cydnidae of the Western Hemisphere. Proceedings of the United.States National Museum, New York, v. 111, p. 337-680, 1960.

GALLO, D.; NAKANO, O.; SILVEIRA NETO, S.; CARVALHO, R.P.L.; BAPTISTA, G.C.; BERTI FILHO, E.; PARRA, J.R.P.; ZUCCHI, R.A.; ALVES, S.B.; VENDRAMIM, J.D.; MARCHINI, L.C., LOPES, J.R.S.; OMOTO, C. Entomologia Agrícola. FEALQ, Piracicaba, SP, Brasil. 2002.

GILBERT, N.; GUTIERREZ, A.P.; FRAZER, B.D.; JONES, R.E. Ecological relationships. San Francisco: W.H. Freeman, 1976. 256 p.

HIGLEY, L.G.; PEDIGO, L.P.; OSTLIE, K.R. Degday: a program for calculating degree-days, and assumption behind the degree-day approach. Environmental Entomology, Lanham, v. 15, n. 5, p. 999-1016, Oct. 1986.

SMITH, J.W. JR; BARFIELD, C.S. Management of preharvest insects. In Peanut Science and Technology; PATTEE, H.E.; YOUNG, C.T. (Eds.) American Peanut Research and Education Society: Yoakum, TX, 1982.

SMITH, J.W. JR; PITTS, J.T. Pest status of Pangaeusbilineatus attacking peanuts in Texas. Journal of Economic Entomology, v.67, n.1, p.111-113, 1974.

ZUCCHI, R.A.; SILVEIRA NETO, S.; NAKANO, O.Guia de identificação de pragas agrícolas.

FEALQ, Piracicaba, SP, Brasil. 1983. 